\title{
RESENHA DE “UMA HISTÓRIA DO FEMINISMO NO BRASIL" DE CÉLI REGINA JARDIM PINTO
}

Cleyton Feitosa ${ }^{1}$

\begin{abstract}
Review of Pinto, Céli Regina Jardim (2003), A history of feminism in Brazil. São Paulo: Publisher Perseu Abramo Foundation.
\end{abstract}

Keywords: Democracy. Social Movements. Feminist Movement. Political Participation.

Céli Pinto possui graduação em Licenciatura em História pela Universidade Federal do Rio Grande do Sul (1972), Mestrado em Ciência Política pela Universidade Federal do Rio Grande do Sul (1979) e Doutorado em Doutorado Em Governo University of Essex (1986). Atualmente é Professora Emérita da Universidade Federal do Rio Grande do Sul (UFRGS). Tem experiência na área de Teoria Política com ênfase em teoria da democracia e teoria feminista. Também atua na área de História do Brasil República, principalmente nos seguintes temas: politica brasileira, feminismo e participação política ${ }^{2}$.

Em Uma História do Feminismo no Brasil, Céli Pinto (2003) classifica a história do Movimento Feminista brasileiro em quatro fases: a primeira, apresenta o surgimento do Movimento Feminista no final do Século XIX e começo do XX; a segunda, aborda o feminismo nascente no contexto da Ditadura Militar; a terceira, narra a mobilização desse Movimento na redemocratização brasileira e, por fim, na quarta e última fase, narra a década de 90 e a expansão das Organizações NãoGovernamentais Feministas.

A primeira fase do feminismo

\footnotetext{
${ }^{1}$ Doutorando em Ciência Política pela Universidade de Brasília (UnB). Mestre em Direitos Humanos pela Universidade Federal de Pernambuco (PPGDH/UFPE). Licenciado em Pedagogia pela Universidade Federal de Pernambuco/Centro Acadêmico do Agreste (UFPE/CAA). Autor do livro "Políticas Públicas LGBT e Construção Democrática no Brasil" (Appris, 2017). É membro do Grupo de Pesquisa Resocie Repensando as Relações entre Sociedade e Estado (IPOL/CNPq). Endereço eletrônico: cleyton_feitosa@hotmail.com.

2 As informações foram extraídas de seu currículo lattes que pode ser acessado na versão completa em: http://lattes.cnpq.br/1527293281181776. Acesso: 06/11/2019.
} 
teve como foco a luta das mulheres pelos direitos políticos mediante a participação eleitoral que correspondia basicamente ao direito de votar e ser votada, já que até o começo do Século $\mathrm{XX}$ era negada às mulheres a igualdade política. Bertha Lutz exerce importante liderança e atividade política pelos direitos das mulheres desde 1920 até a década de 70 quando vem a falecer.

Esse período inicial do Movimento Feminista é caracterizado por três vertentes no seu interior: uma primeira que não define a exclusão da mulher como decorrência da posição de poder do homem (tido como um feminismo bem comportado); uma segunda vertente composta por um feminismo difuso protagonizado por intelectuais (professoras, escritoras, jornalistas), tendo um campo mais vasto de questões como, por exemplo, a educação da mulher, a dominação dos homens e temas delicados para a época, como sexualidade e o divórcio (feminismo menos comportado); e uma terceira vertente que tinha relação com o Movimento Anarquista e com o Partido Comunista priorizando a luta contra a exploração do trabalho

\section{2}

(feminismo ainda menos comportado). Estávamos no Brasil do final do Século XIX e o país passava por um processo de urbanização e industrialização, culminando no surgimento de uma classe operária. $\mathrm{Na}$ Constituição de 1891 as mulheres são esquecidas nos artigos que regulavam as eleições no país. Não é que a Carta Magna as proibia de votar, ela simplesmente ignorava a existência das mulheres, provocando-as a requererem o alistamento eleitoral de muitas mulheres. A luta pelo sufrágio universal do período pretendia ampliar sua base de apoio formando uma opinião pública favorável as suas reivindicações e, por isso, as feministas utilizavam jornais, participavam de eventos públicos e há registros de uma passeata à época.

Em 1910, como resposta a não-aprovação do voto feminino pela Constituinte, um grupo de mulheres fundou $\mathrm{o}$ Partido Republicano Feminino (PRF). Além do voto das mulheres, o Estatuto do Partido Republicano Feminino também falava em emancipação, independência e exploração sexual. O PRF desaparece 
nos últimos anos da década de 1910 quando surge no mesmo período a Federação Brasileira para o Progresso Feminino (FBPF).

A Federação Brasileira para o Progresso Feminino tem estreita relação com a volta ao Brasil, no ano de 1918, de Bertha Lutz que tinha ido a Paris estudar. É interessante observar a trajetória e o perfil de Lutz: filha de uma elite econômica e intelectual. Sua ida para Paris a fez ter contato com ideias feministas do Norte. Chama atenção o fato de que Bertha Lutz possuía reconhecimento e trânsito entre a elite política da época. No ano de 1922, após retornar de uma viagem aos Estados Unidos, é organizado o $1^{\circ}$ Congresso Internacional Feminista no Rio de Janeiro. A partir de então, a FBPF espalha-se pelo país durante a década de 20 com presença nos estados de Minas Gerais, Paraíba, Bahia, São Paulo, Ceará e Rio Grande do Norte, tendo a luta pelo direito ao voto como agenda central. As mulheres que compunham o núcleo duro da FBPF tinham um claro perfil de classe econômica privilegiada.

Buscando apoio na opinião pública, a FBPF entrega um abaixoassinado com 2.000 assinaturas de mulheres ao Senado. Construindo uma relação de aliança com Juvenal Lamartine, então Presidente do estado do Rio Grande do Norte, o estado passa a ser o primeiro a aprovar uma lei autorizando o voto feminino. A primeira eleitora mulher da história do Brasil é oriunda da cidade de Mossoró, que fica no interior do Rio Grande do Norte. É importante ressaltar que a luta pelo voto feminino também era promovida por outras mulheres nos seus estados sem relação com a Federação. A própria Bertha Lutz não era uma líder isenta de críticas: Natércia Silveira, uma advogada gaúcha disputou a liderança da Federação e se retirou posteriormente ao apoiar a candidatura de Getúlio Vargas para a Presidência da República, promovendo um conflito aberto com Lutz que via no engajamento político uma ameaça à luta pelo direito ao voto. Até que no ano de 1932 o novo Código Eleitoral passou a incluir as mulheres no processo eleitoral, reconhecendo seus direitos políticos. A FBPF tentou 
eleger Bertha Lutz para a Constituinte de 1934 conquistando uma suplência e assumindo a titularidade com a morte de um deputado e no mesmo ano a Federação organiza o $3^{\circ}$ Congresso Nacional Feminista. No entanto, com o Golpe de 37 a Federação perde espaço e expressão no cenário brasileiro.

Outra característica dessa primeira fase é o jornalismo feminista. No final do Século XIX e começo do XX fazia parte do Brasil a luta pela liberdade de informação. Nesse contexto, existiam as feministas que sustentavam pequenos jornais, alguns artesanais, em que publicavam artigos e opiniões considerados mais radicais sobre a condição da mulher. Em 1873, Francisca Senhorinha Motta Diniz é a primeira mulher a fundar um jornal brasileiro com o objetivo de divulgar a "causa da mulher" chamado $O$ Sexo Feminino que passaria a se chamar 15 de Novembro do Sexo Feminino.

Além do jornalismo feminista, havia também nesse período o feminismo anarquista. Naquela época o Brasil recebia imigrantes italianos, espanhóis e portugueses que formavam uma massa operária no Rio de Janeiro e São Paulo trazendo ideias libertárias do anarquismo europeu. É nesse momento que ocorrem as primeiras grandes greves do Brasil e se estabelece uma ativa imprensa anarquista no país. As mulheres que faziam parte dessas mobilizações apontavam a opressão masculina, diferentemente das sufragistas.

A primeira manifestação de mulheres próximas ao anarquismo é datada de 1920 e foi lançado pela União das Costureiras, Chapeleiras e Classes Anexas do Rio de Janeiro. Tal manifesto ilustra a posição das mulheres apontando a impossibilidade de conquistar a igualdade sem o reconhecimento da condição da mulher na fábrica. Elas, portanto, chamavam atenção para a questão da diferença que ganharia força na segunda metade do Século XX. Sua pauta tinha na questão do trabalho sua centralidade. Dentre suas denúncias, constavam o fato de que o tempo da mulher era consumido pela dupla jornada de trabalho. Maria Lacerda de Moura, uma destacada anarquista, se opõe às sufragistas acreditando ser tal luta muito restrita e pouco transformadora das relações de 
dominação na sociedade. É interessante notar as diferenças de classe entre as sufragistas da Federação Brasileira para o Progresso Feminino, claramente abastadas, e as anarquistas operárias, trabalhadoras exploradas.

O Golpe de 1937 aniquila a expressão pública de movimentos mais visíveis e expressivos, retomando apenas na Ditadura Militar (19641985) contra o regime repressivo. Como balanço das conquistas dessa primeira fase do feminismo brasileiro temos a conquista do voto como principal vitória das mulheres engajadas no país.

O Movimento Feminista ganha nova expressão após o Golpe de 64, mas é importante entender o contexto mais amplo do Golpe Militar no Brasil: internacionalmente havia uma crítica ao capitalismo estadunidense e ao socialismo do Leste Europeu. Aconteciam nesse cenário movimentos beatnik e hippie nos EUA e os protestos de Maio de 1968 em Paris. Americanas lideradas por Beth Friedman tiram o sutiã em praça pública. Ocorre o lançamento de $O$ Segundo Sexo de Simone de Beauvoir.
No Brasil, havia uma polarização política entre a União Democrática Nacional (UDN), composta por empresários, proprietários de terras, a classe média e forças armadas empunhando a bandeira do anticomunismo versus partidos nacionalistas (Partido Trabalhista Brasileiro) e clandestinos (Partido Comunista Brasileiro), empresários nacionalistas, operários urbanos, movimentos camponeses, intelectuais, estudantes e parte da Igreja Católica. É nesse cenário de polarização política nacional, aliado à Guerra Fria em plano internacional, que ocorre o Golpe Militar de 1964.

A Ditadura Militar vai aprofundando o seu aparato repressivo e a censura extrapola o campo político estendendo-se à questões morais e de costumes. Enquanto o Norte Global passava por momentos de revolução e mudanças culturais, o Brasil entrava em profunda repressão política e perseguição

ideológica/comportamental. Ressurge na década de 70 o Movimento Feminista. Também havia um 
movimento de mulheres ${ }^{3}$ que era composto por organizações de luta contra a carestia, clubes de mães, o movimento pela anistia, entre outras agendas que não exatamente a luta contra a condição inferior da mulher. Há relatos de aproximação desses movimentos de mulheres com $\mathrm{o}$ Movimento Feminista à época. O Movimento vivia tensões internas entre a autonomia da luta específica da causa da mulher e a luta contra a ditadura, além de ser apontado pela esquerda como um desvio pequeno-burguês que trocava a "luta de classes" pela "luta de sexos".

Em 1972 ocorrem dois eventos de natureza distintas: o congresso promovido pelo Conselho Nacional da Mulher liderado pela advogada Rony Medeiros (que era mais conservadora e com trânsito entre a elite política militar) e as primeiras reuniões de grupos de mulheres em São Paulo e Rio de Janeiro (onde também ocorriam reuniões em outros estados), de caráter quase privado, o que seria uma marca do novo feminismo no

\footnotetext{
${ }^{3}$ A diferença entre um movimento e outro reside no fato de que apenas o feminismo questionava
}

Brasil. Essas reuniões eram promovidas por grupos feministas inspirados no feminismo nascente do hemisfério norte e promoviam grupos de reflexão informais que reuniam mulheres que se conheciam previamente e tinham um caráter bastante privado, unidas por laços de amizade, afinidades intelectuais e políticas. A entrada em tais reuniões acontecia por meio de convite. Em alguns casos essas feministas até chegaram a promover atividades públicas, mas o contexto era de pouca oportunidade política em virtude do regime autoritário. As reuniões também tinham um certo caráter terapêutico onde se debatiam assuntos diversos sobre a condição feminina.

Outro fator importante do período da Ditadura Militar é o caso das feministas exiladas. Ativistas exiladas na Europa encontraram um clima diferente do Brasil, propício à contestação a outras formas de hierarquias para além do autoritarismo político e de classes. Ocorre então em 1972 a criação do grupo Latinoessas mudanças. 
Americano de Mulheres fundado por uma ex-militante comunista autoexilada em Paris, Danda Prado, provocando resistência dos homens que acusam o grupo de ser apolítico e de em nada contribuir na luta contra a ditadura. Outro grupo com esse perfil de exílio é o Círculo de Mulheres Brasileiras em Paris (1975-1979), comprometido com o ideário marxista. 1975 é um ano particularmente singular nessa fase do Movimento Feminista. É em 75 que a Organização das Nações Unidas (ONU) define aquele ano como o Ano Internacional da Mulher. É também nesse ano que surge a organização de ativistas acadêmicas na Sociedade Brasileira para o Progresso da Ciência (SBPC) que conforma um outro tipo de feminismo no Brasil, o feminismo acadêmico, e o surgimento da pesquisa científica sobre a condição da mulher no país. Nesse mesmo ano também nasce o Movimento Feminista pela Anistia, fundado por Terezinha Zerbini, que reunia familiares de pessoas exiladas, presas ou desaparecidas.

Também em 1975, a partir de um evento no Rio de Janeiro, é criado o Centro de Desenvolvimento da Mulher Brasileira (CDMB) que se tornava público, diferentemente das reuniões privadas das feministas, e buscava a institucionalização. Também havia uma tensão interna entre as mulheres que se identificavam com uma problemática própria e exclusiva das mulheres versus aquelas que articulavam a luta feminista com a questão da classe. A partir de 77 , o CDMB foi dominado por mulheres marxistas do Partido Comunista prósoviético. Mas ele abrigava três tendências: a marxista (luta de classes), a liberal (direitos individuais) e a radical. E em 1978, o Centro lança um documento intitulado "Carta às Mulheres" que continha reivindicações gerais e específicas para os candidatos. Dentre as reivindicações gerais, encontravam-se a anistia ampla, geral e irrestrita; eleições livres e diretas para todos os cargos; assembleia geral constituinte; fim da carestia e entre as reivindicações específicas tínhamos demandas encontradas nos movimentos de mulheres, como clubes de mães e associações de bairro. 
Uma outra fase do feminismo brasileiro proeminente é o feminismo da redemocratização (Pinto, 2003). Em 1979, acontecia a anistia a presos e exilados políticos e a reforma partidária que acabava com o bipartidarismo da Ditadura Militar composto pela Aliança Renovadora Nacional (ARENA) e Movimento Democrático Brasileiro (MDB). Nessa reforma, as feministas que faziam oposição ao regime militar se dividiram entre os novos Partido dos Trabalhadores (PT) e Partido do Movimento Democrático Brasileiro (PMDB). Ainda assim, houve uma tensão entre feministas que lutavam pela institucionalização e aproximação da esfera estatal e as autonomistas que viam nessa aproximação um processo de cooptação. Também surge um feminismo acadêmico, ancorado no Departamento de Pesquisa da Fundação Carlos Chagas em São Paulo e Núcleos de Pesquisa em Estudos da Mulher. A relação do feminismo com o campo político a partir de 1979 se dá em três áreas diferentes: (i) através da conquista de espaços institucionais como os Conselhos da Condição da
Mulher e Delegacias da Mulher, (ii) por meio da presença de mulheres em cargos eletivos e (iii) por intermédio de formas alternativas de participação política.

$\mathrm{O}$ perigo da perda de autonomia nunca permitiu a existência de um consenso absoluto sobre a criação de conselhos e ministérios que se ocupassem das questões das mulheres. Além disso, uma parte do Movimento Feminista lutava por transformações nas relações de poder que não poderiam advir de uma estreita colaboração entre o Movimento e o Estado. Um dilema emergia nesse contexto: atrelar-se a um partido e ameaçar a autonomia e a unidade do Movimento ou se manter unido e limitar sua participação política à pressão sobre o Estado.

A institucionalização acabou acontecendo de todo modo. Essa institucionalização passa pela vitória do PMDB em governos estaduais e em São Paulo, no qual a vitória de Franco Montoro resulta na criação do primeiro conselho da mulher em 1983 (Conselho Estadual da Condição Feminina). Contudo, ele possuía 
caráter consultivo e propositivo, sem orçamento e era composto por mulheres do PMDB, sofrendo oposição de feministas do PT e de camadas populares que ansiavam por creches. Isso revelava um problema recente da institucionalização: os grupos são suficientemente fortes para romper a impermeabilidade estatal, mas não o bastante para ocupar espaço nas instâncias decisórias.

O Conselho Nacional da Condição da Mulher (CNCM) surge em 1985 a partir do Movimento das Mulheres pelas Diretas Já. Nasce da iniciativa de um grupo de 40 mulheres do PMDB que buscou Tancredo Neves ainda candidato para garantir a criação do órgão. Com a sua morte, José Sarney, seu vice, manteve a promessa e criou o Conselho. O CNCM foi criado junto ao Ministério da Justiça com orçamento próprio, tendo sua presidenta status de Ministra. Era composto por 17 conselheiras nomeadas pelo Ministro da Justiça. Com Collor, o CNCM perdeu seu orçamento e para a sua composição eram indicadas mulheres sem tradição no feminismo. Mesmo com Fernando
Henrique Cardoso o Conselho não recupera o espaço conquistado na década de 80. Ele terá um papel importante na Constituinte de 1988.

Mesmo com a presença de apenas 5,6\% (26 exatamente) mulheres na Câmara dos Deputados sendo formado por um número significativo de mulheres eleitas por partidos de direita (PFL e PDS), elas se autodenominaram "bancada feminina" e apresentaram 30 emendas sobre os direitos das mulheres. Três motivos contribuíram para isso: a proposta de 3 emendas populares promovidas por movimentos de mulheres; a presença do agora chamado Conselho Nacional dos Direitos da Mulher (CNDM) e a postura unificada das constituintes. $\mathrm{O}$ CNDM realizou campanhas de mobilização e elaborou "A Carta das Mulheres" contendo reivindicações gerais e específicas. A questão do aborto não foi explorada no documento como um recuo tático diante do pensamento conservador. A atuação do CNDM em parceria com a bancada feminina resultou em muitos ganhos na versão final da Constituição Federal de 88 que ficou conhecida como a 
Constituição Cidadã.

A década de 80 também é marcada pela entrada na esfera pública de novos temas com ênfase na violência e na saúde. Antes, a questão da violência era tida como um tabu restrita à vida privada. Caso de destaque foi o assassinato de Ângela Diniz pelo seu ex-marido Doca Street. Ele fora absolvido sob o argumento da legítima defesa da honra. Tal sentença provocou uma das primeiras grandes campanhas públicas das feministas e repercutiu na condenação do assassino em segunda instância. Importante marco no enfrentamento à violência contra a mulher no país.

No início da década de 80 é criado o SOS Mulher no Rio de Janeiro (1981) que se constituía num espaço de atendimento à mulheres vítimas de violência e de reflexão e mudança das condições de vida delas. As feministas entraram em crise com o fato de que muitas das mulheres atendidas retornavam para seus companheiros agressores e abandonavam os grupos de reflexão. Surge então um feminismo de prestação de serviço em que as mulheres vítimas encontravam profissionais da saúde e da área jurídica para obter apoio. Esse formato dominaria a década de 90 , por meio das Organizações Não-Governamentais. Em 1985 é criada a primeira Delegacia da Mulher que viria a se popularizar no Brasil. Era uma resposta à violência e ao machismo institucional encontrados nas delegacias comuns. A mulher conquista então o reconhecimento público de que é uma potencial vítima, uma vez que tal problema nunca havia sido observado na esfera pública.

Como dito, outro tema relevante a partir da década de 80 foi o da saúde da mulher. Além de temas tradicionais como os cuidados com a maternidade e com a prevenção do câncer, entra na cena pública temas controversos como o planejamento familiar, a sexualidade e o aborto. Em relação ao planejamento familiar, no Brasil aparecia como um controle de natalidade classista das camadas pobres. As feministas trabalharam na elaboração de projetos de planejamento familiar que atendessem as mulheres pobres sem cair em vieses discriminatórios. Quanto ao aborto, o número anual de abortos ultrapassava a 
casa de um milhão de casos, a maioria sendo feita em condições precárias e arriscadas. A luta pela legalização do aborto causa grande reação da Igreja Católica. Sobre a sexualidade, o debate chega tardiamente no Brasil quando comparado ao Norte Global. Apesar de ser discutido nas reuniões informais da década de 70, o tema não aparecia publicamente para não dificultar a luta por direitos civis e sociais. Além disso, era visto como um tema burguês pela esquerda e uma ameaça à família pela direita.

A década de 80 avança no debate da saúde, tanto pela criação de grupos que buscavam formas alternativas de atendimento à mulher, quanto pela implantação do Programa de Atenção Integral à Saúde da Mulher (PAISM). O PAISM foi sem dúvida uma das mais bem-sucedidas intervenções de um movimento social organizado na esfera das políticas públicas e em 1986 aconteceu a Conferência Nacional de Saúde e Direitos da Mulher, em Brasília.

A década de 80 também é formada por um feminismo acadêmico em ebulição nas universidades públicas brasileiras. Na verdade, o feminismo desde as suas origens sempre reuniu intelectuais, diferentemente de movimentos mais populares, fortemente excluídos do acesso aos grandes centros de produção do conhecimento. As reuniões da segunda fase, na década de 70, reuniam professoras e profissionais liberais das áreas das Ciências Humanas e Sociais.

A tese de livre-docência defendida em 1967 por Heleieth Saffioti, orientada por Florestan Fernandes, chamada $A$ Mulher na Sociedade de Classes: mito e realidade é considerado texto fundador e definitivo na produção acadêmica sobre a mulher. Tal produção aumenta no final da década de 70 através de concursos de dotação de recursos da Fundação Carlos Chagas (FCC) com financiamento da Fundação Ford. Também é na FCC que surge em 1981 o jornal Mulherio, importante publicação feminista da década. Outro importante espaço de produção sobre a mulher é o das associações nacionais das diversas áreas do conhecimento: ANPOCS, ANPED, ANPOL, entre outras. É desse período o surgimento 
de núcleos de estudos sobre a mulher.

O primeiro surge na Pontifícia Universidade Católica do Rio em 1982 por iniciativa de uma das pioneiras, Fanny Tabak. Em 1991 acontece o $1^{\circ}$ Encontro Nacional de Núcleos em São Paulo. Um exemplo de núcleo que se tornou referência é o Pagu da Unicamp. Em 1992 é criada a Redor - Rede Feminista Norte e Nordeste de Estudos e Pesquisas sobre a Mulher e Relações de Gênero. Destacam-se também núcleos e grupos de pesquisa da UnB, da USP e da UFBA. Também chama atenção pela qualidade científica a Revista Estudos Feministas, criada em 1992 pela Universidade Federal de Santa Catarina.

Chegando à década de 90 temos um outro cenário, marcado pela retração dos movimentos sociais e aumento das ONGs Feministas, apontando para uma profissionalização da militância. Percebe-se também um feminismo difuso que se espraia para diferentes setores da sociedade através da diminuição do espaço legítimo para a profusão de piadas machistas, racistas ou homofóbicas e contra a discriminação de trabalhadores e trabalhadoras em função do sexo. Também ocorre um crescente debate sobre assédio sexual nas Casas Legislativas do país.

Quanto à participação política, a questão aparece sob duas formas: a frágil participação das mulheres nas esferas estritas da política - campo eleitoral e governamental - e as formas alternativas de participação das mulheres que lhes permite êxitos expressivos na elaboração de políticas públicas. Nesse sentido, as ONGs possuem papel importante nessas formas alternativas de participação política e na difusão de temas diversos como a de mulheres rurais, mulheres portadoras de HIV, mulheres parlamentares, negras, prostitutas, etc., gerando a segmentação das lutas e à ideia de feminismos, no plural, em oposição àquele branco, de classe média, intelectual e heterossexual. No entanto, elas são financiadas por agências internacionais e governamentais que terceirizam responsabilidades/serviços e define a agenda de atuação da sociedade civil. É importante ressaltar que a expansão das ONGs não eliminou a existência de 
mulheres em movimentos, sindicatos, partidos políticos, entre outros espaços movimentalistas.

No campo da política, destacase o Centro Feminista de Estudos e Assessoria (CFEMEA), criado em 1989 em Brasília, intermediando o campo político e o movimento de mulheres. Elas defendem projetos, propõem emendas, assessoram a bancada de mulheres, divulgando atividades no seu jornal Fêmea. Divulga, através de suas publicações impressas e na internet, as tramitações e decisões governamentais, falando para lideranças e uma certa elite do movimento, não para mulheres em geral ou de movimentos populares. A Articulação da Mulher Brasileira (AMB) é um contraponto desse tipo de atuação na esfera da alta política, assessorando e organizando movimentos de base. Foi criada para preparar a ida das mulheres brasileiras à Conferência Mundial de Pequim em 1995.

Em 1991 temos a Criação da Rede Nacional Feminista de Saúde e Direitos Reprodutivos conhecida como RedeSaúde que congrega 110 filiadas em 20 estados e recebe verbas do Ministério da Saúde para realizar atendimentos. Tem tido ação destacada na defesa de implantação do serviço de aborto legal nos hospitais públicos. Reúne-se com a Coordenação da Área Técnica de Saúde da Mulher do Ministério da Saúde e com a Central Única dos Trabalhadores, a CUT, sinalizando concomitantemente ocupação em Conselhos e diálogos com a sociedade civil.

Em 1998 é elaborado pelo CFEMEA, CEPIA (Cidadania, Estudo, Pesquisa, Informação e Ação), Themis (Themis Assessoria Jurídica) e Cladem (Comitê Latino-Americano e do Caribe para a Defesa dos Direitos da Mulher) em parceria com a Comissão de Direitos Humanos da Câmara dos Deputados, um documento intitulado Propostas para o Estado Brasileiro Niveis Federal, Estadual e Municipal Medidas Concretas para o Enfrentamento da Violência Contra a Mulher no

Ambito

Doméstico/Familiar.

Para o Poder Executivo o documento recomenda políticas públicas, campanhas e programas 
educativos, inclusão curricular. Para o Poder Legislativo, recomenda a aprovação de leis que garantam recursos orçamentários e reformulação de códigos. Para o Judiciário, recomenda medidas de sensibilização das autoridades judiciárias como a promoção de cursos para os funcionários. Todas essas iniciativas expressam formas alternativas de participação política da mulher.

Há ainda outras organizações que estão mais focadas no empoderamento das mulheres (Geledés, por exemplo que atua em gênero e raça), outras como o SOS Corpo de Recife atuam na área da saúde da mulher e pretendem construir espaços públicos de discussão e conscientização. $\mathrm{O}$ Movimento Feminista na virada do milênio é composto por uma gama de organizações que atuam hoje no Brasil e que variam muito de atuação de uma pra outra.

Como se pode ver no decorrer do texto, o livro Uma história do feminismo no Brasil se constitui como leitura obrigatória para aqueles e aquelas que se debruçam sobre os estudos de gênero e sexualidade. Embora o livro já esteja um pouco desatualizado (o ano de publicação é 2003) e não aborde momentos relevantes mais recentes, como a aprovação da Lei Maria da Penha e seus efeitos na sociedade brasileira ou a retomada de um movimento conservador, capitaneado por fundamentalistas evangélicos nas casas parlamentares, nem explore com mais atenção a diversidade interna das correntes no interior da militância, a obra explora os principais momentos do ativismo feminista no Brasil em articulação com a conjuntura mais ampla do país e da tortuosa construção democrática brasileira.

\section{Referências bibliográficas}

Pinto, Céli Regina Jardim (2003), Uma história do feminismo no Brasil. São Paulo: Editora Fundação Perseu Abramo 